\title{
A Study on Effective EFL Lecturers at Makassar, Indonesia
}

\author{
Ahmad Thalib \\ Universitas Negeri Makassar \\ Makassar, Indonesia
}

\author{
Baso Jabu \\ Universitas Negeri Makassar \\ Makassar, Indonesia \\ basojabu@yahoo.com
}

\author{
Asriati \\ Universitas Negeri Makassar \\ Makassar, Indonesia
}

\begin{abstract}
This research aims to investigate the perception of the students on effective EFL lecturers' characteristics and the most important characteristic based on the professional, pedagogical, and social competences, personal qualities, and intra and intercultural awareness. This research used descriptive mixed method with concurrent triangulation. The source of data was from 129 English department students of Universitas Negeri Makassar. To analyze the data, the researchers compared the results of quantitative and qualitative data at the same time. This research found out that the characteristics of effective English language lecturers based on the students' perceptions can be seen from: pedagogical competence: using creative and innovative teaching methods, creating joyful and comfortable class circumstances, using variative teaching methods with variety of challenging activities and assignments, and having good presentation skills; personal qualities: disciplined, friendly, humorous, assertive, charismatic, fair, caring, and understanding students; professional competence: mastering English well, having teaching experiences, and reflecting and evaluating their teaching methods; social competence: treating the students fairly, creating emotional relationship with students and their surroundings; and intra- and inter-cultural awareness: understanding cultural differences well. The most important characteristics needed by the effective English language lecturers are their pedagogical competence and personal qualities.
\end{abstract}

Keywords—perception; competences; effective english lecturer; characteristics

\section{INTRODUCTION}

Teaching a foreign language is not easy. The fact is that the students' levels of English ability vary because of they are from different areas and backgrounds. Therefore, a lecturer of English is expected to be able to understand a variety of conditions of the students. Moreover, characteristics and skills in teaching may affect students' ability to master the subjects taught. Some researchers have discussed this condition. Darling-Hammond reported the results of his research on the quality of teachers and students' achievement [1]. Teacher quality is a factor that proves to be very influential on students' performance compared to the class size and the length of learning. Next, if the teachers are better prepared in teaching, they can be a powerful influence on students' achievement compared to students' background factors, such as poverty, language background, and the status of minorities in society. Teachers' condition may not be different from lecturers. Lecturers and teachers are educators who have a similar role with a little difference. Therefore, they are used interchangeably in this study.

Harmer mentions that several factors, such as extrinsic motivation, intrinsic motivation, and success are likely to have a strong effect on the success and failure of students in language learning [2]. Of these factors, intrinsic factor is considered as an important factor that depends on the students. Intrinsic motivation of students consists of four major factors. The first factor is the physical condition of the students. The second factor is the learning method they use in learning. The third factor is the teacher as a very important factor that affects the intrinsic motivation of students. The fourth factor is the factor of success.

The characteristics of effective teachers or lecturers can vary according to some experts. Stronge, Tucker, \& Hindman describe the prerequisites for effective teaching that is associated with the effective teachers as follows: verbal ability, content knowledge, professional education, lecturer/teacher certification, and teaching experience [3].

The level of experience of the teachers used is determined by the teachers themselves whether they want to use their experience and formulate new types of teaching methods in the classroom depends on themselves.

Furthermore, Stronge states that an effective quality teacher may be summarized in four comprehensive reports that describe an effective teacher for students of all levels of ability and background: technical knowledge, pedagogical skills, interpersonal skills, and personal qualities [4].

In line with the previous theories of effective English teachers, Park \& Lee state that effective English language teachers can be categorized into three main categories: English language skills, pedagogical knowledge, and social-affective skills [5]. The three categories should be emphasized in defining effective English teachers. Brown formulates some of the characteristics of good language teachers by dividing them into categories, such as technical knowledge, pedagogical skills, interpersonal skills, and personal qualities [6].

It can be concluded that the characteristics of effective English language teachers have in common with the four basic 
competencies that must be owned by professional educators, teachers, in Indonesia. However, as educators in the field of language, characteristics of effective English language teachers have some important differences as intrapersonal and interpersonal skills. The effective language teachers must master both the cultural values of the target language country and of the country where they teach. Primarily it is intended for English teachers who teach English as a foreign language such as in Indonesia. Teachers must recognize and understand the cultural differences between English culture and Indonesian culture.

A country like Indonesia, which has hundreds of tribes, cultures, traditions and languages of course have many differences with English as it is from a western country. This is especially important because Makassar is the capital of South Sulawesi as one of the leading provinces in eastern Indonesia. Eastern culture and western culture must be managed effectively by an English teacher. Effective English language teachers should pay more attention to the proper use of material that is contextual to be used for students in Makassar.

In this study, the current researchers emphasize the characteristics of effective English language lecturers as lecturers who can own and control the competence and quality of the following: professional competence, pedagogical competence, social competence, personal qualities, and intracultural and intercultural awareness.

\section{Methodology}

This research is a combined descriptive quantitative research (mixed method) with the concurrent triangulation model. The data source is 129 students of the English Department, Universitas Negeri Makassar.

In collecting data, the research instrument for the quantitative study is a questionnaire for effective English lecturers. For the qualitative research, the researchers act as the key research instruments. The researchers play an important role in this research because they act as observers and interviewers of this study to collect valid data.

The results of quantitative and qualitative research are compared that are conducted simultaneously. The qualitative data are analyzed based on the steps by Miles \& Huberman, i.e. data reduction, data display, and conclusion or verification [7].

\section{FINDING AND DISCUSSION}

\section{A. Students' Perceptions regarding Characteristics of Effective English Lecturers}

Professional competence is one of the characteristics that should be owned by the effective English lecturers. Based on the findings, there are some characteristics that the students mentioned as part of the professional competence that must be possessed by lecturers: (a) good command of English and the components therein, (b) sufficient experience in teaching and evaluating teaching experience and knowing how to recognize the emotions of students and more familiar with the materials to be taught, and (c) reflecting and evaluating teaching methods, and making improvements to their teaching.

Pedagogical competence is one of the key competencies which is closely related to the teaching and learning process in the classroom. A classroom is a place for creating interaction between lecturer and students. An effective English lecturer should have a pedagogical competence: (a) having an exciting class atmosphere that is fun and not boring, (b) preparing syllabus and learning devices before teaching including the material before teaching, and (c) having good presentation skills to make it easy to follow the courses and not making them feeling bored.

Social competence also has an important role in determining the effectiveness of a lecturer of English. An effective lecturer should have the characteristics of (a) not discriminating against students in teaching both in terms of ability and background of his students; he does not provide different treatment to students regardless of their background, of their behavior in the classroom, and of their performance in the classroom, if the students need assistance, and (b) building emotional closeness with students and how lecturers interact with students in the classroom or outside the classroom is very important to be created. Creating a good relationship between teachers and students is an important thing to be done by a lecturer. This shows that the effective lecturers according to the students' perception need to establish a good relationship with the students.

The effectiveness of a lecturer can also be seen from the personal qualities he possessed. Based on data obtained from the students there are some personal qualities they put forward that must be owned by an effective English lecturer: (a) disciplined and become models for their students, such as not to be late for class; (b) friendly, a lecturer should be able to interact with students to create emotional closeness; (c) humorous, having a sense of humor as ice breaking and close relation, and to make it easier to interact and build closeness with students because humor can bridge the tension and stiffness that may arise between lecturers and students; (d) firm and charismatic lecturers make students better appreciating the lecturers; (e) fair which means not discriminating among students, which is also important in scoring the students, and (f) attentive and understanding students' condition in order that the students also feel comfortable being taught by the lecturer and even it can increase the students' motivation to learn.

Effective English language lecturers as foreign language instructors in Indonesia need to understand the cultural differences not only between the Indonesian culture and the culture of the countries that use the English language but also the different cultures of Indonesia which must be taken by students from their respective areas. Particularly dialect differences that students have. Based on the interviews when students are given the option to be taught by native speakers of English and Indonesian speakers who can speak English, most of the students choose to be taught by the Indonesian people because they have worries if they are taught by foreign lecturers. The lecturers will not understand Indonesian culture that is often heavily used by the students especially dialectal 
differences. Yet they remain open to be taught by foreign lecturers as long as the lecturer already understands the cultures of Indonesia.

\section{B. The Most Important Characteristics to Have by the Effective English Lecturers}

Table 1.1 shows the ranking of each item of statement obtained from questionnaire data by looking at the highest total score of every item of statement. The assumption is that the higher the total score of each item of statement, the more from data sources choose strongly agree and agree with the statements because the scores for strongly agree and agree are 5 and 4, undecided, disagree, and strongly disagree have scores of 3, 2 and 1 respectively.

TABLE I.

COMPETENCY RANKING BASED ON TOTAL SCORE

\begin{tabular}{|l|l|l|}
\hline \multicolumn{1}{|c|}{ Types of Competence } & \multicolumn{1}{|c|}{$\begin{array}{c}\text { Ranking of } \\
\text { Statement Items } \\
(\mathbf{1 - 1 0})\end{array}$} & $\begin{array}{c}\text { Competency } \\
\text { Ranking }\end{array}$ \\
\hline Professional Competence & 4 and 5 & 3 \\
\hline Pedagogical Competence & 1,3, and 7 & 1 \\
\hline Social Competence & 8 & 4 \\
\hline Personal Quality & $2,6,9$, and 10 & 2 \\
\hline $\begin{array}{l}\text { Intra-Intercultural } \\
\text { Understanding }\end{array}$ & - & 5 \\
\hline
\end{tabular}

Table 1.1 shows that effective English language lecturers are lecturers who have an adequate pedagogical competence and have good personal qualities.

From the statement items on pedagogical competence, 2 of which fall into three major categories and obtain the greatest number, which means that a lot of students strongly agreed or agreed with the statement item. The statement "the class atmosphere taught is fun and not boring" ranks 1 and the statement "the ability to explain is good" ranks 2. Both statements are strongly agreed by the students.

The statement items regarding the personal qualities rank second most widely agreed by the students. Personal qualities of the lecturers received ranks 2, 6, 9, and 10. "Friendly", "appreciate the efforts of the students (in doing assignments and exams)", "creative", and "discipline" are the four personal qualities that earn the highest ratings by the most total score.

The statement items regarding professional competence and social competence are also included in a 10 large-scale highest scores, but not as much as the score obtained from the score statement of pedagogical competence and personal qualities of effective English lecturers. These competencies fall into five highest scores. By achieving ranks 4 and 5, the statement "good command of English" and "good English pronunciation" associated with the English language skills of lecturers are also considered important.

The aspect of intra-cultural and inter-cultural understanding is not getting a high score. It illustrates that this aspect is not deemed reasonably necessary to be a priority competence required by an effective English lecturer. The low scores obtained from the statement items regarding this competency show that most students are undecided and disagree with the statement items that represent this aspect.

\section{CONCLUSION}

Based on the findings of research and discussion in the previous part, the following conclusions can be drawn 1) the characteristics of effective English lecturers based on the students' perceptions can be viewed in terms of pedagogical competencies, such as having creative and innovative teaching strategies, and having good presentation skills; personal qualities, such as disciplined and humorous; professional competence, such as mastering English well and having experience in teaching; social competence, such as undiscriminating students and building emotional attachment with the students and all the faculties and staff on campus; and understanding of intra and inter-culture, that is an effective English lecturer is required to have a good understanding of the cultural differences between Indonesian and foreign cultures as well as intra-culture within Indonesia. 2) The most important characteristics of effective English lecturers are pedagogical competence and personal qualities, although the three other competencies (professional competence, social competence, and intra and inter-cultural understanding) are also considered to support the effectiveness of the lecturers.

\section{References}

[1] L. Darling-Hammond, 'Teacher quality and student achievement: A review of state policy evidence. University of Washington: Center for the Study of Teaching and Policy. Retrieved July 30, 2012'. 1999.

[2] J. Harmer, 'The practice of English language teaching', London/New York, 1991.

[3] J. H. Stronge, P. D. Tucker, and J. L. Hindman, Handbook for qualities of effective teachers. Ascd, 2004.

[4] J. H. Stronge, Qualities of effective teachers. ASCD, 2007.

[5] G.-P. Park and H.-W. Lee, 'The characteristics of effective English teachers as perceived by high school teachers and students in Korea', Asia Pacific Educ. Rev., vol. 7, no. 2, pp. 236-248, 2006.

[6] H. D. Brown, 'Teaching by principles. An interactive approach to language pedagogy. New York: AW Longman'. Inc, 2001.

[7] M. B. Miles and A. M. Huberman, Qualitative data analysis: An expanded sourcebook. sage, 1994. 